\title{
HYDROLOGIC IMPACT OF CLIMATE CHANGE ON POYANG LAKE WETLAND, CHINA
}

\author{
ZHAN, M. J. - WANG, H. Q. - LI, B. Z. - YIN, J. M.* \\ Jiangxi Provincial Eco-meteorological Centre \\ No. 323 Aixihu 2nd Road, NanChang City, Jiangxi Province, China \\ *Corresponding author \\ e-mail: yjm163@sina.com; phone: +86-791-8271-3183; fax: +86-791-8271-3189
}

(Received 15t Mar 2019; accepted 21 ${ }^{\text {st }}$ May 2019)

\begin{abstract}
This study developed hydrologic models based on satellite remote sensing data from 2002 to 2010. Daily meteorological and hydrological data (1959-2010) were used as model inputs to analyse the relationships between meteorological factors and water area, and to calculate the daily water area and mean reduced water area on an annual basis to analyse the trend of changes. By analysing BCC-CSM1-1 model data, the study derived a qualitative assessment of the future water area of the Poyang Lake Basin, China. The following results were found. (1) The water area had shrunk substantially since the 1990s, especially during the 2000s. Because of aridification, the water area had decreased by $22.5 \%$ from 1845 $\mathrm{km}^{2}$ in the $1980 \mathrm{~s}$ to $1430 \mathrm{~km}^{2}$ in the 2000s. (2) Since 1990, the first day of its wet season had become delayed and the final day had advanced. Generally, the number of wet season days had reduced while that of the dry season has increased. (3) In all future scenarios, extreme events were projected to occur more frequently, suggesting dramatic volatility in water resources and great frequency of droughts, which would exacerbate the shrinking of Poyang Lake and represent a severe threat to its water security.
\end{abstract}

Keywords: Poyang Lake, water area, wet season, dry season, RCPs scenario

\section{Introduction}

Although wetlands cover only about $6 \%$ of the earth's surface, they provide many services for humans, such as food, water, recreation and space for living. Climate change is recognized as a threat to the health of wetland systems. Major changes in global climate can be summarized as follows: (1) changes in total precipitation and precipitation pattern; (2) increase temperature and evapotranspiration, especially in high latitude; and (3) an increase in extreme climate events (IPCC, 2013; Junk et al., 2013). These changes will certainly induce variations in the structure, pattern, and function of wetlands by modifying temperature, precipitation, hydrology, and evapotranspiration (Erwin and Gardner, 2009). In North America, climate change will change rainfall patterns, thus affecting runoff and groundwater inflows to wetlands. In general, a decrease in precipitation or an increase in evapotranspiration will result in less-frequent flooding of existing wetlands. The magnitude and rate of climate change could alter the hydrology of the Great Lakes and affect wetland ecosystems. Because of an increased frequency and duration of low water levels, key wetlands are at risk, particularly those that are impeded from adapting to the new water level conditions by man-made structures or geomorphic conditions (Sierszen, 2012).

In China, especially in north China, it is difficult to predict the loss of the wetlands because of the climate change. As the global mean temperature continues to increase, the glacier in Qinghai-Tibet Plateau accelerates dissolution. The area of some wetlands has shrunk, while some wetland areas have increased, such as Ulan Ula Lake (Yan et al., 2014). But in south China, due to the combined effect of human activities and 
climate change, the wetland area is shrinking, such as Dongting Lake, Poyang Lake and so on (Liu et al., 2013; Cheng et al., 2016).

Located on the southern bank of the middle and lower reaches of the Yangtze River, Poyang Lake is the largest freshwater lake in China. It covers an area of $162,200 \mathrm{~km}^{2}$ and it accounts for 9\% of the Yangtze River Basin. The lake is one of the 10 largest ecological reserves in China and it is a major global ecoregion, as designated by the World Wide Fund for Nature. It plays an essential role in the protection of worldwide biodiversity, management of ecological security, safeguarding of people's livelihoods and property, and implementation of national water resource strategies (Hu et al., 2007). However, because of the impacts of climate change and anthropogenic activity, the wetland of Poyang Lake has "aged" rapidly in recent years, as evidenced in the lake sediments and by the shrinking of the lake and wetland areas (Jie et al., 2007; Qian and Dan, 2010; Jian et al., 2014).

The development of remote sensing technology has enabled extensive analysis of the water area of Poyang Lake to be conducted. For example, Zhang et al. (2012) adopted satellite remote sensing data acquired during 1991-2000 to analyze the water area dynamics of Poyang Lake. Using statistical analysis to couple the water area data with water levels measured by hydrologic stations during the same period, they established a relationship between water area and water level that modeled water area changes well, despite inherent errors between the wetland and water areas based on the remote sensing analysis. Dai et al. (2013) compared Landsat images of Poyang Lake from around 1990 and 2000 and they reported a substantial reduction in water area.

This study used remote sensing data to analyze the change of area of Poyang Lake's main body and its adjacent waters during 2000-2010. The objectives were to determine the relationship between meteorological conditions and water level, simulate the daily water area of Poyang Lake's wetland from 1959 to 2008, and discuss its annual trend of change over the past 50 years. Furthermore, the study adopted future Representative Concentration Pathways (RCPs) scenario data provided by the BCC-CSM1-1 model, developed by the National Climate Center of the China Meteorological Administration. These projections were used to discuss potential changes in climatic and basin factors, surface runoff and hydrologic extremum, and the potential impact of temperature change on the water area of Poyang Lake. The findings constitute a reference for the provision of management solutions by decision-making departments and science-based suggestions for sustainable socioeconomic development.

\section{Data}

\section{Meteorological data}

Daily meteorological data from Jan. 1, 1959 to Dec. 31, 2010 were provided by the Meteorological Bureau of Jiangxi Province. The dataset comprised almost complete and regular data records (20:00 to 20:00 Beijing time) from a reasonably dense and welldistributed network of 79 meteorological stations located within the lake basin (Fig. 1). Missing temperature and precipitation data in some stations records accounted for $\leq 0.5 \%$ of the total dataset. The missing data were compensated based on inverse distance weighting using data from the nearest four stations (Appleton and Adlam, 2012); therefore, the missing data were considered not to compromise the mean value and the total value calculated on annual and monthly bases. 


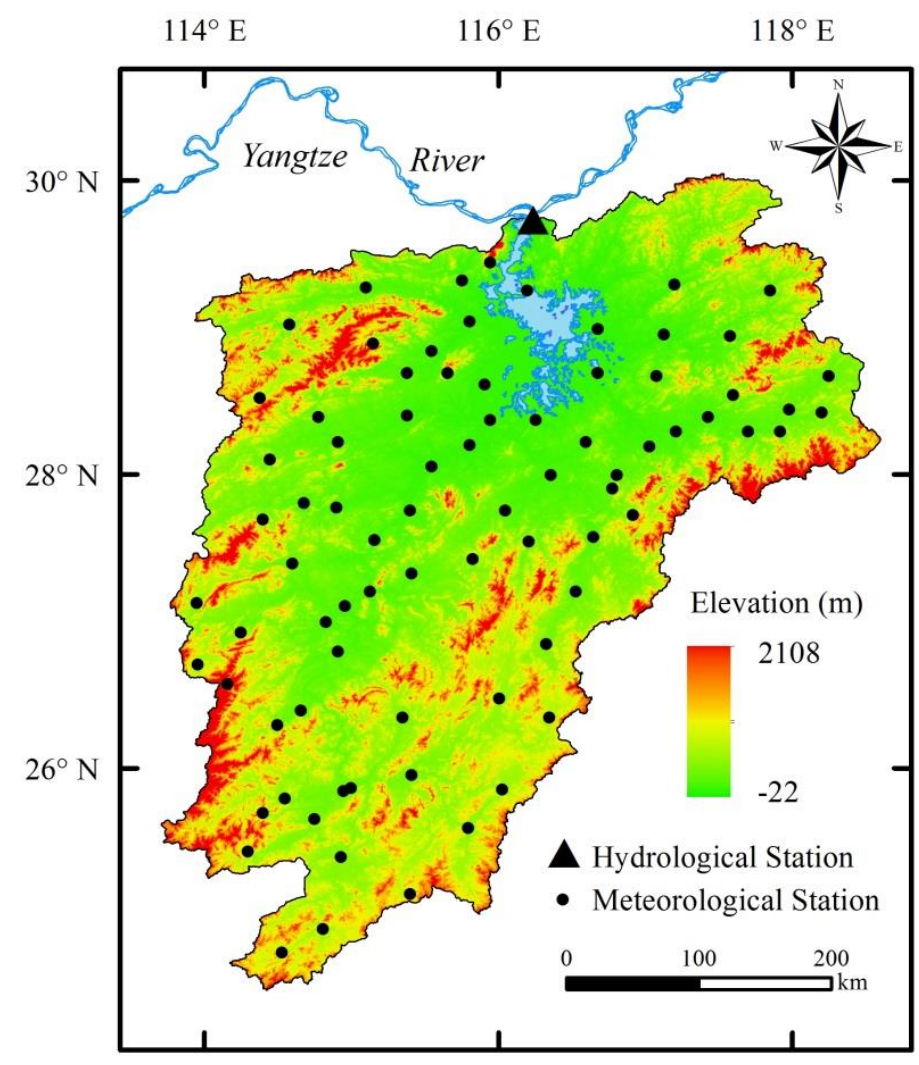

Figure 1. Meteorological and hydrological (Hu Kou) stations in the Poyang Lake Basin

\section{Hydrological data}

The Hukou Hydrologic Station is the control station located at the point where Poyang Lake discharges into the Yangtze River. The data recorded at Hukou reflect the level of Poyang Lake, which is governed by the levels of both the Yangtze River and the five major rivers that flow into the lake (Fig. 1; Hu et al., 2010). The hydrological data used in this study comprised daily water levels (Wusong Elevation) from 1961 to 2010 recorded at Hukou and Xingzi stations, provided by the Water Resources Department of Jiangxi Province.

\section{Satellite remote sensing image data}

The satellite remote sensing data of the water area of Poyang Lake (2002-2010) comprised 130 images acquired from the Poyang Lake Satellite Remote Sensing Data Bulletin released by the Meteorological Institute of Jiangxi Province. Figure 2 shows the water area of Poyang Lake measured by remote sensing on June 4, 2010.

\section{Climate model data}

To predict future global and regional climate change, future emissions of greenhouse gases and sulfate aerosols need to be considered and these are included in the Special Report on Emissions Scenarios. In 2014, the IPCC suggested the use of radiation intensity per unit area to reflect Representative Concentration Pathway (RCP) scenarios 
over the next 100 years. Different RCP scenarios (e.g., high, medium, and low) can be chosen based on projections of greenhouse gas emissions and equivalent $\mathrm{CO}_{2}$ concentrations (IPCC, 2014; Metz et al., 2007).

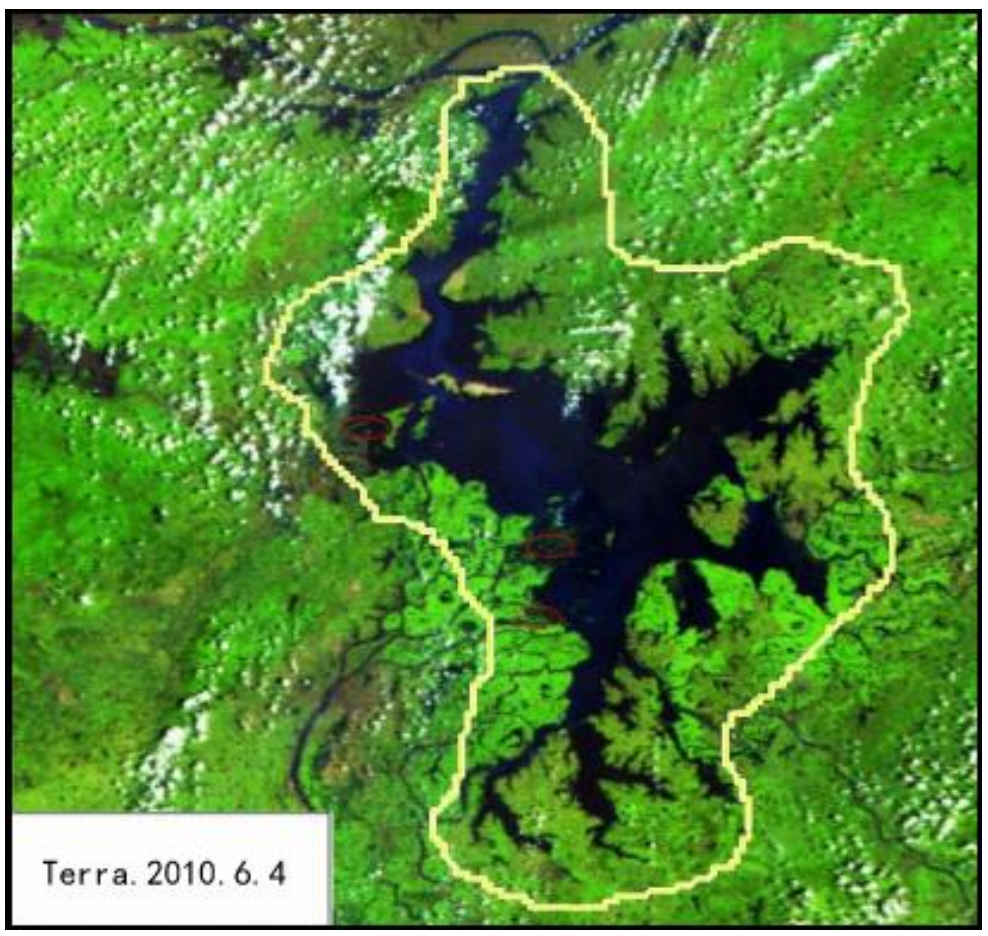

Figure 2. Remote sensing image of Poyang Lake, acquired on June 4, 2010

The study used data from the BCC-CSM1-1 model, developed by the National Climate Center. The model included three scenarios: RCP26, RCP45, and RCP85 with data resolution of $1^{\circ} \times 1^{\circ}$. The data comprised four parameters: mean temperature, highest and lowest temperatures, and precipitation spanning from Jan. 1, 1980 to Dec. 31, 2060. The model has been compared with other global climate models proposed for IPCC AR5, and it has been found to have better capacity in simulating climate (National Climate Center, 2012) in the monsoon belt of East Asia. Analysis of a control run of the BCC-CSM1-1 model by Zhang et al. (2011) and by Xin et al. (2013) indicated that it could satisfactorily reproduce the temperature and precipitation in China.

The simulation capability of the BCC-CSM1-1 model in terms of the daily temperature and precipitation in the area of Poyang Lake from 1986 to 2005 can be assessed using a Taylor diagram (Taylor, 2001; Xu et al., 2016). Comparisons of the correlation coefficients and the root mean square deviations of the observed data (19862005) with the BCC-CSM1-1 simulated data (1986-2005) show whether the model results are applicable to the Poyang Lake Basin. The Taylor diagram presented in Figure 3 shows the correlation coefficients for the temporal and spatial distributions of temperature are 0.68 and 0.67 , respectively, while those for precipitation are 0.58 and 0.45 , respectively. All the root mean square deviations are $<0.5$. Therefore, the BCCCSM1-1 model is considered capable of simulating the daily temperature and precipitation at the station level for 1986-2005, indicating the suitability of the simulation data for the analysis of the spatiotemporal variations of temperature and precipitation. 


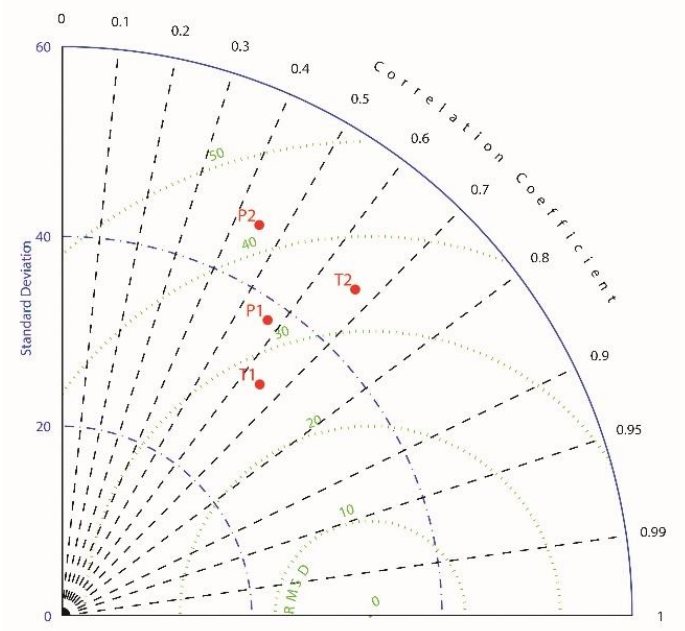

Figure 3. Taylor diagram of temperature (Temporal distribution: T1; Spatial distribution: T2) and precipitation (Temporal distribution: P1; Spatial distribution: P2) for the BCC-CSM1-1 model

\section{Methodology}

\section{Classification of water area}

This study classified the water area of Poyang Lake using the following scheme. The historically largest water boundary was taken as its outer boundary and its historically smallest water boundary was adopted as its inner boundary. We considered the area outside the outer boundary as land not submerged by water and the area inside the inner boundary as land covered by the lake. The water boundary of the lake moves within the outer and inner boundaries on a daily basis. The area between the water and inner boundaries was defined as the expanded water area and the area within the outer and water boundaries was defined as the reduced water area (see Fig. 4).

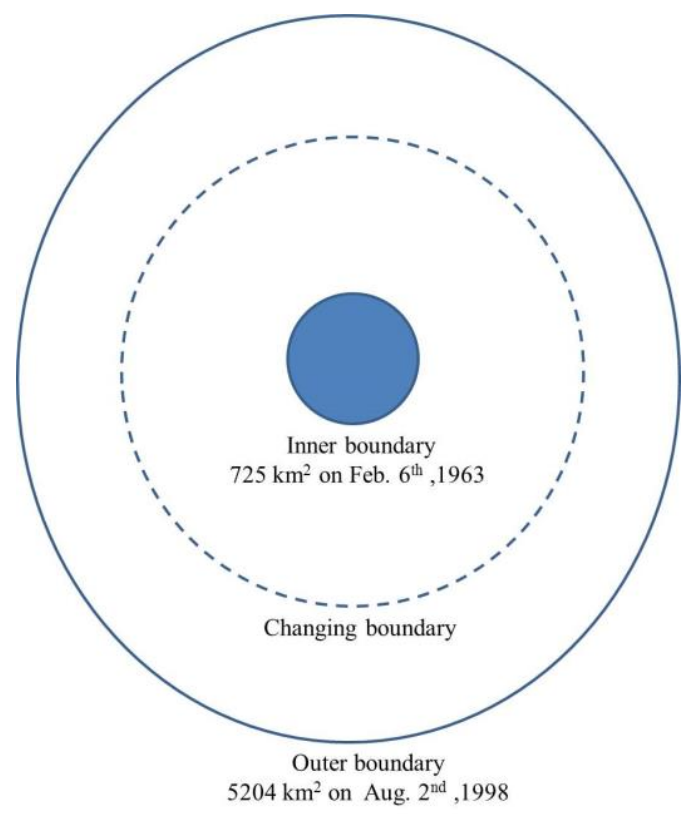

Figure 4. Schematic of definition of water area of Poyang Lake 


\section{Water area model of Poyang Lake}

Land reclamation constitutes a major process via which the land resource of lake areas in the southern plains of China has been developed and exploited. The harnessing of reclaimed land to develop agriculture (Zhang et al., 2015) has long been practiced in the wetland area of Poyang Lake. Since the founding of the People's Republic of China, unchecked land reclamation has been undertaken. For example, the area of reclaimed land in the 1950s, 1960s, and 1970s was 394.9, 793.4, and $211.7 \mathrm{~km}^{2}$, respectively. However, by the $1980 \mathrm{~s}$, the situation was more controlled with only $66.9 \mathrm{~km}^{2}$ of land reclaimed. Since the flooding that occurred in 1998, a policy of returning farmland to lakes has been phased in (Zhu and Kang, 2017). By the end of 2001, 900,000 residents had been resettled and the water area increased by over $1000 \mathrm{~km}^{2}$. To avoid the influence of anthropogenic activity on the water area of Poyang Lake, this study used data collected from 2002 to 2009, after the return of farmland to the lake had been completed. These data included 98 samples of water area measured by remote sensing, water level measured at Hukou Station, and mean temperature and precipitation measured by the meteorological stations surrounding the Poyang Lake wetland. Stepwise regression analysis (Arunajadai, 2009) revealed the strongest correlations between the water area determined by remote sensing and water level measured at Hukou Station, and between the 30-d accumulative mean temperature and accumulative precipitation. We established a functional relationship between water area, Hukou water level, and meteorological conditions as below:

$$
\mathrm{Y}=-1.029 \mathrm{X} 1+0.202 \times 2+312.476 \mathrm{X} 3-991.585
$$

where $Y$ is the simulated water area of Poyang Lake, $X_{1}$ is the 30 -d accumulative mean temperature, $X_{2}$ is the 30 -d accumulative mean precipitation, and $X_{3}$ is the water level at Hukou Station on that day. Based on 14 sets of remote sensing data of water area, water level measured at Hukou Station, and meteorological data, it was verified that this model could satisfactorily simulate the water area of Poyang Lake with a correlation coefficient of up to 0.986 and mean relative error of only $5.6 \%$ (Table 1). No significant difference between simulated and measured data by F-test. In general, the simulation achieves the desired effect.

Inputting the data on temperature, precipitation, and water level at Hukou Station during the study period into Equation 1 produced the largest and smallest water areas of 5204 (August 2, 1998; Hukou water level: $22.53 \mathrm{~m}$ ) and $725 \mathrm{~km}^{2}$ (February 6, 1963; Hukou water level: $5.91 \mathrm{~m}$ ), respectively. Therefore, this study adopted $5204 \mathrm{~km}^{2}$ as the outer boundary and $725 \mathrm{~km}^{2}$ as the inner boundary.

\section{Results}

\section{Changing trends of drought and flood of the Poyang Lake Basin}

To analyze the trend of change of the Poyang Lake wetland, we supposed the water area within the outer boundary and within the inner boundary was $S_{\text {MAX }}$ and $S_{\text {MIN }}$, respectively, and the water area on a certain day was $S$. Therefore, we defined the following:

$$
S_{\text {expanded lake area }}=S-S_{\mathrm{MIN}}
$$


and

$$
S_{\text {reduced lake area }}=S_{\mathrm{MAX}}-S \text {. }
$$

We used Equation 1 to calculate the daily water area from 1959 to 2008. Its difference from the outer and inner boundaries was determined as the daily expanded or reduced water areas, respectively. Figure 5 shows the annual mean expanded or reduced water areas. According to the statistics in the Chronicle of Meteorological Disasters in China-Jiangxi Volume (CMA, 2010) and the Yearbook of Climate-Related Disasters in China (CMA, 2014), basin-wide severe flooding occurred in 1970, 1973, 1975, 1995, and 1998. Taking 1998 as an example, 1329 villages and towns from 79 counties (cities or districts) were badly affected with direct economic losses of RMB38.714 billion. Basin-wide severe drought has occurred in 1963, 1971, 1972, 1978, 1986, 1988, 2001, 2003, 2004, 2006, and 2007. Taking 2007 as an example, 352,000 ha of crops were affected by drought and 64,000 ha of winter crops could not be sown. Overall, 760,000 people and 310,000 large livestock lacked adequate supplies of drinking water.

Table 1. Simulation tests of the water area of Poyang Lake in 2010

\begin{tabular}{|c|c|c|c|c|c|c|}
\hline Data & $\begin{array}{c}\text { Water level of } \\
\text { Hukou (m) }\end{array}$ & $\begin{array}{c}\text { Remote } \\
\text { sensing of } \\
\text { water area } \\
\left(\mathbf{k m}^{2}\right)\end{array}$ & $\begin{array}{l}\text { Accumulated } \\
\text { temperature of } \\
\mathbf{3 0} \text { days }\left({ }^{\circ} \mathbf{C}\right)\end{array}$ & $\begin{array}{l}\text { Accumulated } \\
\text { precipitation of } \\
\mathbf{3 0} \text { days }(\mathbf{m m})\end{array}$ & $\begin{array}{c}\text { Simulated } \\
\text { area }\left(\mathbf{k m}^{2}\right)\end{array}$ & $\begin{array}{l}\text { Relative } \\
\text { error }\end{array}$ \\
\hline 02.21 & 8.98 & 1582 & 236.1 & 145.9 & 1601 & 1.2 \\
\hline 03.12 & 11.71 & 2298 & 285.2 & 196.8 & 2414 & 5.0 \\
\hline 03.26 & 10.28 & 1757 & 410.4 & 224.0 & 1844 & 4.9 \\
\hline 05.23 & 16.61 & 3300 & 642.2 & 329.1 & 3604 & 9.2 \\
\hline 05.24 & 16.87 & 3390 & 646.8 & 330.9 & 3681 & 8.6 \\
\hline 05.25 & 17.16 & 3429 & 652.1 & 330.9 & 3766 & 9.8 \\
\hline 06.04 & 16.97 & 3367 & 673.0 & 364.9 & 3692 & 9.7 \\
\hline 06.21 & 18.17 & 3855 & 711.1 & 369.0 & 4029 & 4.5 \\
\hline 06.22 & 18.17 & 3855 & 714.4 & 338.4 & 4019 & 4.3 \\
\hline 08.12 & 18.83 & 3688 & 897.4 & 100.8 & 3989 & 8.2 \\
\hline 09.18 & 16.89 & 3293 & 834.8 & 136.3 & 3455 & 4.9 \\
\hline 10.08 & 14.74 & 2922 & 734.1 & 74.2 & 2874 & 1.6 \\
\hline 10.28 & 12.85 & 2342 & 590.0 & 70.7 & 2431 & 3.8 \\
\hline 11.08 & 11.2 & 1932 & 519.3 & 62.5 & 1986 & 2.8 \\
\hline \multicolumn{6}{|c|}{ Average } & 5.6 \\
\hline
\end{tabular}

The time series of changing wetland area presented in Figure 5 reflects the occurrence of flood and drought disasters in the Poyang Lake Basin. Figure 5 shows that since 1990 the wetland area of Poyang Lake has had a trend of reduction. Particularly since 2000, several severe droughts have exacerbated this trend (the trend passed the 0.01 reliability test). The water area of Poyang Lake has shrunk substantially from the 1990s, especially during the 2000s. Because of aridification, the water area has shrunk by $22.5 \%$ from $1845 \mathrm{~km}^{2}$ in the $1980 \mathrm{~s}$ to $1430 \mathrm{~km}^{2}$ in the $2000 \mathrm{~s}$. 


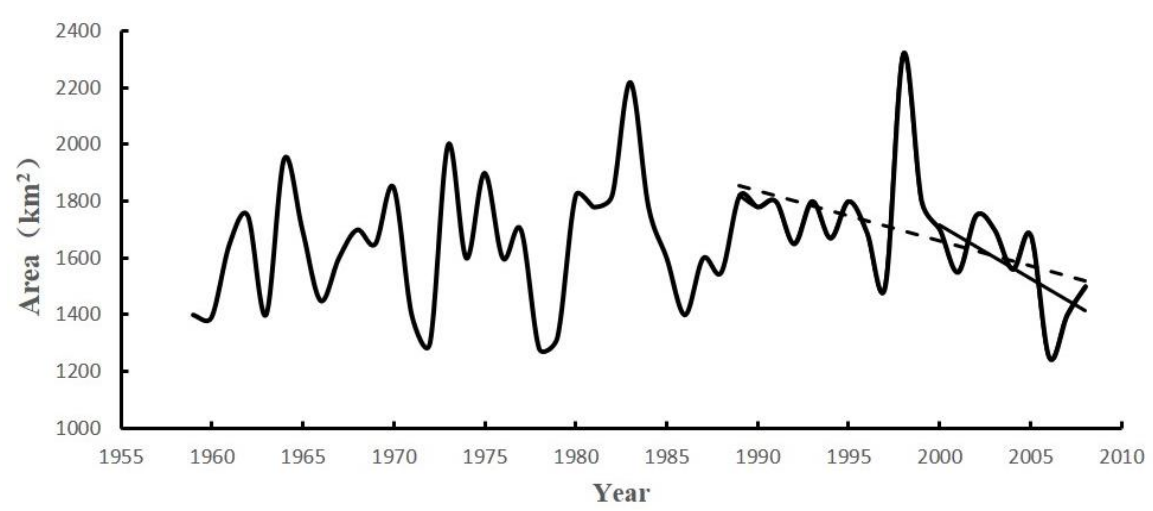

Figure 5. Temporal variation of wetland area of the Poyang Lake Basin (1959-2008)

\section{Changing trend of wet season of Poyang Lake Basin}

The wet and dry seasons of the Poyang Lake Basin were determined based on the water level at the Xingzi Hydrologic Station. When its water level was $>13.39 \mathrm{~m}$, we considered the area to be in the wet season and the first day of such an occurrence was denoted the first day of the wet season (final day of the dry season). When its water level was $<10.22 \mathrm{~m}$, we considered the area to be in the dry season and the first day of such an occurrence was denoted the first day of the dry season (final day of the wet season). The period between the first and final days of the wet season was called the wet season of Poyang Lake. Using daily hydrological data from Xingzi Station (19592009), we calculated the annual first and final days of the wet season and the number of wet season days.

According to Figures 6-8, the first day of the wet season of Poyang Lake has had a tendency to become delayed (the trend passed the 0.05 reliability test). Conversely, the final day of the wet season of Poyang Lake has had a tendency to become advanced (the trend did not pass the reliability test). Generally, the number of days of the wet season of Poyang Lake has decreased since 1990 (the trend passed the 0.05 reliability test). This reduction has led to large-scale wetland loss and degradation, stunting the growth and development of both plants and animals. Taking the dry season from August 2006 to April 2007 as an example, it is evident that the eco-environment of the lake area has been influenced by the effects of climate change. Droughts have given rise to serious ecological issues, including the drying up of lake branches, degradation of lakeside wetland, and desertification of the lakebed.

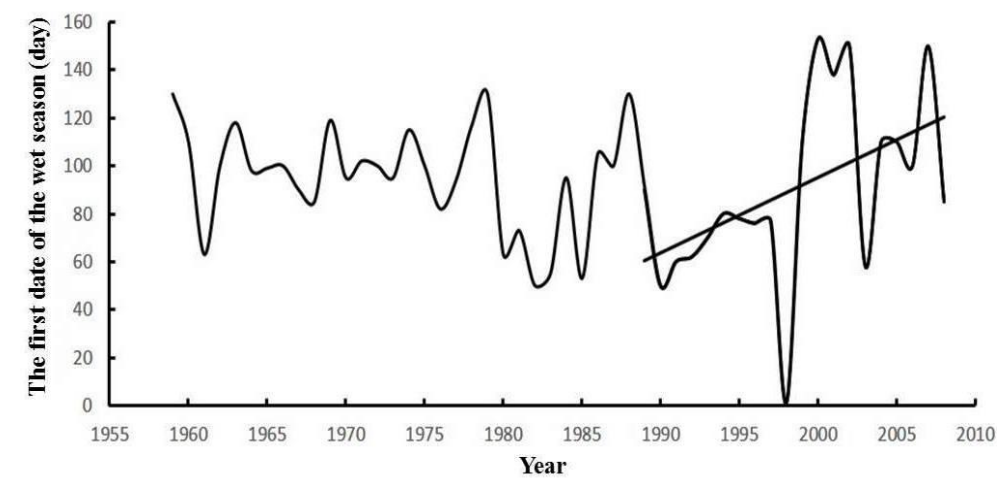

Figure 6. Temporal variation of first day of the wet season (1959-2008) 


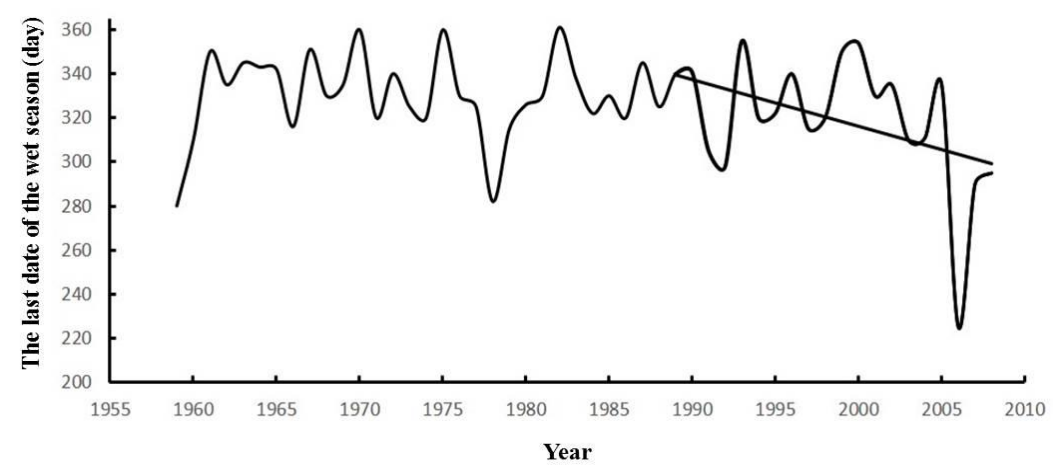

Figure 7. Temporal variation of the final day of the wet season (1959-2008)

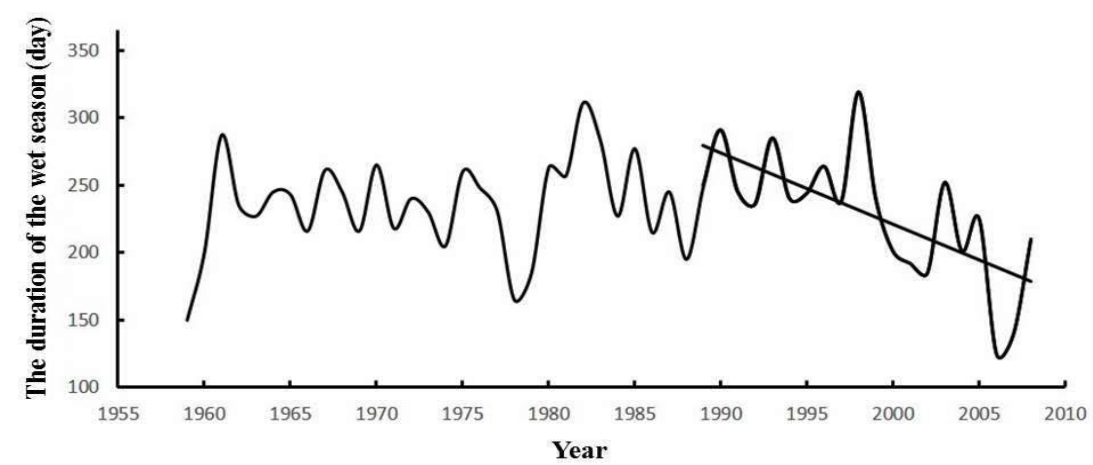

Figure 8. Temporal variation of duration of wet season (1959-2008)

\section{Climate prediction}

Data from the BCC-CSM1-1 model, developed by the National Climate Center, is capable of simulating the climatic conditions of the Poyang Lake Basin. Based on systematic analyses, Zhan et al. (2013) verified the capability of the BCC-CSM1-1 model in simulating the spatial and temporal trends of temperature.

\section{Temperature prediction}

As shown in Figure 9, under the three future climate change scenarios (RCP2.6, RCP4.5, and RCP8.5), the annual mean temperature of the Poyang Lake Basin would increase to different extents from 2011 to 2060. It would increase the least under the RCP2.6 scenario and it would increase the most under the RCP8.5 scenario. The rates of temperature rise under the RCP2.6, RCP4.5, and RCP8.5 scenarios would be $0.26,0.37$, and $0.44{ }^{\circ} \mathrm{C} / \mathrm{a}$, respectively. The mean temperature, however, would be highest $\left(17.7^{\circ} \mathrm{C}\right)$ under the RCP4.5 scenario and lowest $\left(16.9^{\circ} \mathrm{C}\right)$ under the RCP8.5 scenario.

\section{Precipitation prediction}

As shown in Figure 10 and Table 2, under the three RCP climate change scenarios, precipitation in the Poyang Lake Basin from 2011 to 2060 would not change overall, although interannual fluctuation would be apparent. The annual mean precipitation would be lowest under the RCP8.5 scenario, while it would be similarly relatively 
higher under the RCP2.6 and RCP4.5 scenarios. In terms of interdecadal precipitation distribution, the trends seen under the RCP2.6 and RCP4.5 scenarios would be consistent with a $\mathrm{W}$-shaped pattern, i.e., reflecting a process of "fall-rise-fall." Under the RCP8.5 scenario, the Poyang Lake Basin could experience a prominent trend toward a hotter and wetter climate.

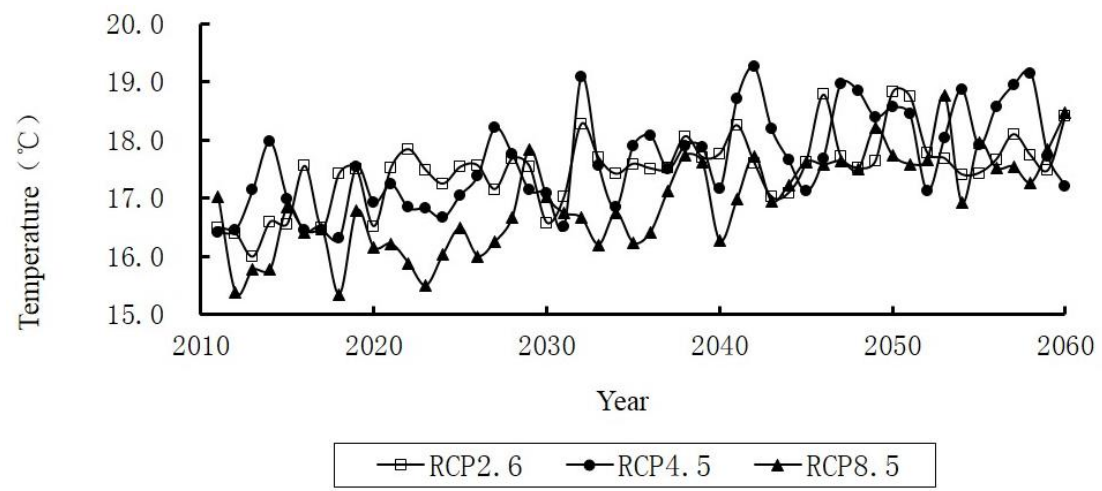

Figure 9. Temporal variation of annual mean temperature under different RCP scenarios (2011-2060)

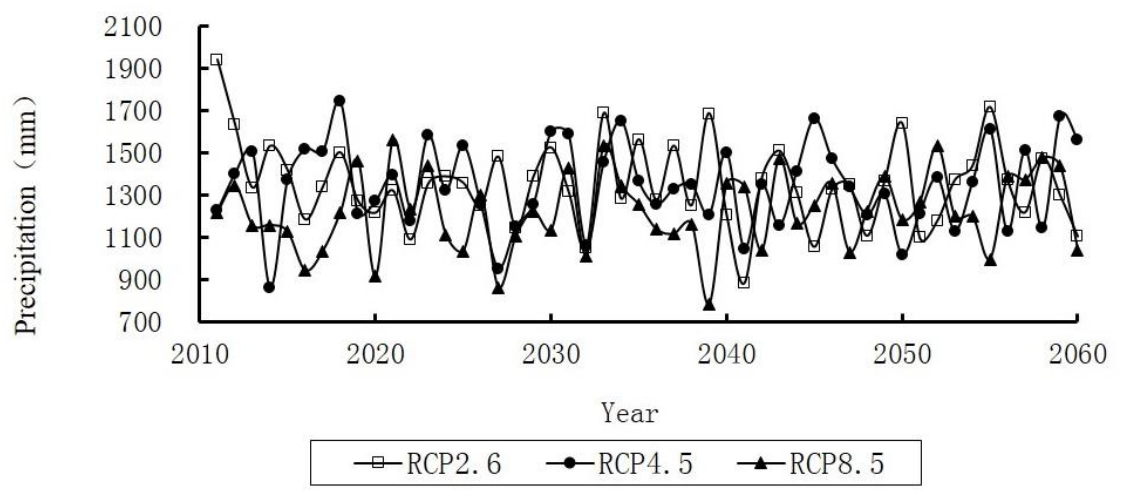

Figure 10. Temporal variation of annual precipitation under different RCP scenarios (20112060)

Table 2. Decadal annual precipitation of the Poyang Lake Basin under different RCP scenarios (2011-2060)

\begin{tabular}{c|c|c|c|c|c|c}
\hline $\begin{array}{r}\text { Precipitation } \\
(\mathbf{m m})\end{array}$ & $\mathbf{2 0 1 0 s}$ & $\mathbf{2 0 2 0 s}$ & $\mathbf{2 0 3 0 s}$ & $\mathbf{2 0 1 0 s}$ & $\mathbf{2 0 1 0 s}$ & $\mathbf{2 0 1 1 - 2 0 6 0}$ \\
\hline Scenarios & 1437 & 1329 & 1385 & 1292 & 1326 & 1354 \\
RCP2.6 & 1362 & 1323 & 1376 & 1296 & 1371 & 1345 \\
RCP4.5 & 1157 & 1200 & 1212 & 1245 & 1290 & 1221 \\
RCP8.5 &
\end{tabular}

\section{Changing trend of precipitation extremum}

Extreme precipitation events can be represented by two quantiles, e.g., the 10th and 90th percentiles of annual precipitation (Guan et al., 2015; Zhang et al., 2015). Table 3 
lists the threshold values of extreme events in the Poyang Lake Basin. It is shown that from 2011 to 2060, dry years with $10 \%$ probability of occurrence would increase obviously under all three RCP scenarios but the increase would be greatest under the RCP4.5 and RCP8.5 scenarios. Over the past 50 years, wet years with $10 \%$ probability of occurrence remained largely constant under the RCP2.6 scenario but they decreased in number in both the RCP4.5 and the RCP8.5 scenarios. In general, under all three scenarios, extreme events would be expected to occur more frequently, suggesting dramatic volatility in water resources and greater frequency of droughts, which would exacerbate the shrinking of Poyang Lake and represent a severe threat to its water security.

Table 3. Frequency of extreme events in the Poyang Lake Basin from 2011 to 2060 under the different RCP scenarios

\begin{tabular}{c|c|c|c|c}
\hline \multicolumn{2}{c|}{$\begin{array}{c}\text { Extreme precipitation from 1981 to } \\
\text { 2005 (mm) }\end{array}$} & \multicolumn{3}{c}{ Extreme precipitation from 2011 to 2060 (mm) } \\
\hline The 10th percentile & $\begin{array}{c}\text { The 90th } \\
\text { percentile }\end{array}$ & & $\begin{array}{c}\text { Times lower than the } \\
\text { 10th percentile }\end{array}$ & $\begin{array}{c}\text { Times higher than } \\
\text { the 10th percentile }\end{array}$ \\
\hline \multirow{3}{*}{1098} & \multirow{2}{*}{1607} & RCP2.6 & 6 & 5 \\
& & RCP4.5 & 10 & 1 \\
& RCP8.5 & 13 & 2 \\
\hline
\end{tabular}

\section{Conclusions and discussion}

The Poyang Lake Basin is sensitive to the effects of climate change. Particularly since the 1990s, it has witnessed a rapid rise in temperature, fewer rainfall days, and increased precipitation intensity, which have increased the frequencies of floods in summer and of droughts in spring and autumn (Wang et al., 2009; Wei et al., 2015). Since the 2000s, with even greater temperature rises and slight falls in amounts of precipitation, the Poyang Lake Basin has faced severe challenges of aridification and shrinkage of the lake area. Based on hydrological data from the Wuhe and Xingzi stations (1956-2007), a study by Min and Dan (2010) yielded almost identical results to those derived from the present work.

1. A statistical model built using hydrological and meteorological data was verified capable of reflecting changes in the water area of Poyang Lake. Based on the difference between the water area and the outer and inner boundaries, this study redefined and reclassified the area of the Poyang Lake wetland. The results showed that the change of wetland area satisfactorily reflected the variation between flood and drought throughout the entire basin. Since 1990, and particularly since 2000, acute reduction of the wetland area has accelerated its aridification.

2. Using the water level of the Xingzi Station as a benchmark, the first and final days of the wet season (first and final days of the dry season) of Poyang Lake were analyzed. It was found that since 1990 the first day has become delayed and that the final day (first day of the dry season) has advanced. The number of wet season days has decreased significantly and the wetland area is in the process of dramatic shrinkage.

3. Under the RCP2.6, RCP4.5, and RCP8.5 scenarios, it was discovered that the temperature from 2011 to 2060 would continue to rise in the Poyang Lake Basin. Although the precipitation amounts would remain similar, extreme droughts would occur with greater frequency and the water area would fluctuate more substantially, 
which would exacerbate the shrinkage and degradation of the water area, introducing greater instability to the ecological system.

Irrespective of whether based on observed or remotely sensed data, previous research has largely agreed that the area of Poyang Lake has shrunk from the 1960s to the 2000s (Min and Dan, 2010; Feng et al., 2011; Gan and Liu, 2011). However, considering the influence of the Three Gorges Dam (Wu et al., 2011; Mei et al., 2015; Liu et al., 2017), the future of the Poyang Lake Basin is more difficult to forecast. Based on future climate data, this study predicted exacerbation of the shrinkage of Poyang Lake. To overcome inadequacies identified in this research, our future work will use additional climate model data and a hydrological model to consider the effects of the Three Gorges Dam.

Acknowledgements. This study was supported by the CMA Climate Change Science Fund (CCSF (201607) and the CDM FUND “Jiangxi Climate Change Adaptation Program" (2014102).

\section{REFERENCES}

[1] Appleton, J. D., Adlam, K. A. M. (2012): Geogenic control on soil chemistry in urban areas: a novel method for urban geochemical mapping using parent material classified data. - Applied Geochemistry 27(1): 161-170.

[2] Arunajadai, S. G. (2009): Stepwise logistic regression. - Anesthesia and Analgesia 109(1): 285-285.

[3] Cheng, J. X., Xu, L. G., Jiang, J. H. et al. (2016): The research of runoff responses to climate change and human activities in the Dongting Lake catchment. - Journal of AgoEnvironment Science 35(11): 2146-2153.

[4] China Meteorological Adminisitration (CMA) (2010): Chronicle of Meteorological Disasters in China - Jiangxi Volume. - China Meteorological Publishing, Beijing.

[5] China Meteorological Adminisitration (CMA) (2014): Yearbook of Climate Related Disasters China. - China Meteorological Publishing, Beijing.

[6] Dai, Z., Zhang, W., Chen, X. (2013): Monitoring TSM by HJ CCD imagery index in Poyang Lake. - Geomatics and Information Science of Wuhan University 38(11): 13031307.

[7] Erwin, K. L., Gardner, R. C. (2009): Wetlands and global climate change: the role of wetland restoration in a changing world. - Wetlands Ecology and Management 17(1): 71.

[8] Feng, L., Hu, C., Chen, X. et al. (2011): MODIS observations of the bottom topography and its inter-annual variability of Poyang Lake. - Remote Sensing of Environment 115(10): 2729-2741.

[9] Gan, X. Y., Liu, C. L. (2011): Analysis of drought in Poyang Lake. - Meteorological and Environmental Research 5: 38-40.

[10] Guan, Y., Zhang, X., Zheng, F. et al. (2015): Trends and variability of daily temperature extremes during 1960-2012 in the Yangtze River Basin, China. - International Journal of Climatology 124(3): 79-94.

[11] Hu, M. L., Wu, Z. Q., Liu, Y. L. (2010): Characteristics of water level and its effects on water environmental factors in Hukou area of Poyang Lake. - Journal of Hydrogeology 48: 542-553.

[12] Hu, Q., Feng, S., Guo, H. (2007): Interactions of the Yangtze River flow and hydrologic processes of the Poyang Lake, China. - Journal of Hydrology 347(1-2): 90-100.

[13] IPCC (2013): Climate Change 2013: The Physical Science Basis. Contribution of Working Group I to the Fifth Assessment Report of IPCC the Intergovernmental Panel on Climate Change. - Cambridge University Publishing, UK, and New York. 
[14] IPCC (2014): Climate Change 2014: Impacts, adaptation and vulnerability. Contribution of Working Group II to the Fifth Assessment Report of IPCC the Intergovernmental Panel on Climate Change. - Cambridge University Publishing, UK and New York.

[15] Jian, H.G, Jia, J., Kettner, A. J. (2014): Changes in water and sediment exchange between the Changjiang River and Poyang Lake under natural and anthropogenic conditions, China. - Science of the Total Environment 481C(1): 542-553.

[16] Jie, E. L., Li, X. J., Liu, S. Y. (2007): Analysis of dynamic changes of the wetland of poyang lake and its causes. - Acta Agriculturae Universitatis Jiangxiensis 42: 36-45.

[17] Junk, W. J., An, S., Finlayson, C. M. et al. (2013): Current state of knowledge regarding the world's wetlands and their future under global climate change: a synthesis. - Aquatic Sciences 75(1): 151-167.

[18] Liu, Y., You, H., Cheng, X. et al. (2013): Estimation of variation of Poyang Lake area based on long-term MODIS observations. - Journal of Geo-Information Science 15(3): 469-475.

[19] Liu, Z., Guo, S., Guo, J. et al. (2017): The impact of Three Gorges Reservoir refill operation on water levels in Poyang Lake, China. - Stochastic Environmental Research and Risk Assessment 31(4): 879-891.

[20] Mei, X., Dai, Z., Du, J. et al. (2015): Linkage between Three Gorges Dam impacts and the dramatic recessions in China's largest freshwater lake, Poyang Lake. - Scientific Reports. DOI: 10.1038/srep18197.

[21] Metz, B., Davidson, O. R., Bosch, P. R. (2007): Climate Change 2007: Mitigation. Contribution of Working Group III to the Fourth Assessment Report of the Intergovernmental Panel on Climate Change. - Cambridge University Publishing, UK and New York.

[22] Min, Q., Dan, M. (2010): Drought change characteristics and drought protection countermeasures for Poyanghu Lake Basin. - Journal of China Hydrology 30(1): 84-88.

[23] National Climate Center (2012): Data set of Regional model prediction in China Version 2.0. - China Meteorological Publishing, Beijing.

[24] Qian, M., Dan, M. (2010): Drought change characteristics and drought protection countermeasures for Poyang Lake Basin. - Journal of China Hydrology 30(1): 84-88.

[25] Sierszen, M. E., Morrice, J. A., Trebitz, A. S. et al. (2012): A review of selected ecosystem services provided by coastal wetlands of the Laurentian Great Lakes. Aquatic Ecosystem Health and Management 15(1): 92-106.

[26] Taylor, K. E. (2001): Summarizing multiple aspects of model performance in a single diagram. - Journal of Geophysical Research Atmospheres 106(D7): 7183-7192. DOI: 10.1029/2000JD900719.

[27] Wang, H. Q., Zhao, G. N., Peng, J. et al. (2009): Precipitation characteristics over five major river systems of Poyang drainage areas in recent 50 years. - Resources and Environment in the Yangtze Basin 18(7): 615-619.

[28] Wei, J., Knoche, H. R., Kunstmann, H. (2015): Contribution of transpiration and evaporation to precipitation: an ET-Tagging study for the Poyang Lake region in Southeast China. - Journal of Geophysical Research: Atmospheres 120(14): 6845-6864.

[29] Wu, L. H., Li, M., Guo, Y. Y. et al. (2011): Influence of Three Gorges Project on Water quality of Poyang Lake. - Procedia Environmental Sciences 10(1): 1496-1501.

[30] Xin, X. G., Wu, T. W., Li, J. L. et al. (2013): How well does BCC_CSM1.1 reproduce the 20th century climate change over China? - Atmospheric and Oceanic Science Letters 6(1): 21-26.

[31] Xu, Z., Hou, Z., Han, Y. et al. (2016): A diagram for evaluating multiple aspects of model performance in simulating vector fields. - Geoscientific Model Development 9(12): 1-25.

[32] Yan, Q., Liao, J. J., Shen, G. Z. (2014): Remote sensing analysis and simulation of change of Ulan-Ul Lake in the past 40 years. - Remote Sensing for Land and Resources 26(1): 152-157. 
[33] Zhan, M. J., Yin, J. M., Kong, P. (2013): Prediction on possible climate change of Poyang Lake Basin in the future 50 years, under RCP scenario. - Science Technology and Engineering 13(34): 107-115.

[34] Zhang, J., Wei, H. U., Liu, Y. (2015): Response of soil microbial functional diversity to different land-use types in wetland of Poyang Lake, China. - Acta Ecologica Sinica 35(4): 234-245.

[35] Zhang, L., Dong, M., Wu, T. (2011): Changes in precipitation extremes over Eastern China simulated by the Beijing Climate Center - Climate System Model (BCC_CSM1.0). - Climate Research 50(2): 227-245.

[36] Zhang, L., Fraedrich, K. Zhu, X. et al. (2015): Interannual variability of winter precipitation in Southeast China. - Theoretical and Applied Climatology 119(1-2): 229238.

[37] Zhang, N., Wen, W., Yin, W. (2012): Estimate the area of the Poyang Lake using satellite remote sensing data and analyze its relationship with water level. - Remote Sensing Technology and Application 36: 45-54.

[38] Zhu, H. G., Kang, L. Y. (2017): An analysis on farmers' alternative choice to substitute livelihood and its influencing factors in returning farmland to wetland. A case study of Poyang Lake area. - Journal of Jiangsu University 19(3): 7-14. 